\title{
DAVID DIOP, Rhétorique nègre au XVIII siècle
}

\section{Roberto Ferraroni}

\section{(2) OpenEdition \\ Journals}

\section{Edizione digitale}

URL: https://journals.openedition.org/studifrancesi/44378

DOI: 10.4000/studifrancesi.44378

ISSN: 2421-5856

\section{Editore}

Rosenberg \& Sellier

\section{Edizione cartacea}

Data di pubblicazione: 1 juin 2021

Paginazione: 250-251

ISSN: 0039-2944

Notizia bibliografica digitale

Roberto Ferraroni, «DAVID DIOP, Rhétorique nègre au xvIII siècle», Studi Francesi [Online], 193 (LXV | I) |

2021, online dal 01 juillet 2021, consultato il 15 octobre 2022. URL: http://journals.openedition.org/ studifrancesi/44378; DOI: https://doi.org/10.4000/studifrancesi.44378

Questo documento è stato generato automaticamente il 15 octobre 2022.

\section{(c)}

Creative Commons - Attribuzione - Non commerciale - Non opere derivate 4.0 Internazionale - CC BYNC-ND 4.0

https://creativecommons.org/licenses/by-nc-nd/4.0/ 


\title{
DAVID DIOP, Rhétorique nègre au XVIII siècle
}

\author{
Roberto Ferraroni
}

\section{NOTIZIA}

DAVID DIOP, Rhétorique nègre au XVIII siècle, Paris, Classiques Garnier, 2018, 403 pp.

1 Uno spunto molto interessante muove la stesura del saggio di Diop: lo studioso si propone di affrontare la problematica della retorica nera nel Settecento; un tale approccio potrebbe sembrare azzardato in quanto, come è noto, le persone di colore occupavano, in quel periodo storico, una posizione sociale inferiore rispetto alla popolazione bianca. Infatti nel saggio non si parla del modo di esprimersi della popolazione di colore, ma piuttosto di quello che gli schiavisti, i missionari, gli abolizionisti, i filosofi "facevano dire" agli uomini di colore nei loro diari e racconti di viaggio.

2 Le intenzioni dell'autore vengono messe subito in evidenza dalla prefazione e dall'introduzione, così come sono poi riassunte nella conclusione finale. Il testo presenta una struttura molto chiara e precisa: è equamente diviso in tre parti ognuna delle quali dedicata a un aspetto ben definito. Ogni parte presenta un'introduzione e una conclusione, che dimostrano un metodo ben organizzato e limpido. Nella prima parte, «Rhétorique de la parole rapportée dans la littérature viatique au XVIII siècle», l'autore affronta il tema dei racconti di viaggio, così come venivano presentati da missionari, esploratori, colonizzatori, che naturalmente davano una visione parziale e filtrata dal loro personale giudizio degli uomini che incontravano nei nuovi territori da loro esplorati. I discorsi riportati delle popolazioni africane vengono rimodulati in questi racconti per diverse ragioni: in primo luogo non si poteva permettere che al pubblico arrivasse la totalità dei pensieri espressi dagli uomini di colore, ma era necessario far loro dire solo ciò che era lecito che dicessero; si tratta quindi di una sorta di censura imposta dai conquistatori ai conquistati. In secondo luogo, era molto difficile 
riuscire a tradurre correttamente tutti i termini delle lingue africane, riuscire a coglierne tutte le sfaccettature; "importando" quindi il loro linguaggio nel francese dell'epoca, esse venivano necessariamente cambiate, adattate alla lingua europea, perdendo di conseguenza la reale forza e la loro ricchezza, sia da un punto di vista linguistico, che dei contenuti.

3 La seconda parte, «Mots et bons mots africains dans quelques relations de voyage au XVIII ${ }^{\mathrm{e}}$ siècle», continua l'argomento trattato nel capitolo precedente, analizzando $\mathrm{i}$ motivi per cui nelle relazioni di viaggio "les mots et bons mots africains" sono spesso rimpiazzati da traduzioni improprie, quasi privati della loro identità e natura che avevano nella lingua d'origine. L'autore mette in evidenza come le relazioni dei viaggiatori, scritte sia per motivi legati allo studio ma anche per motivi legati al commercio, e che avessero quindi una volontà evangelizzatrice o meno, abbiano sempre la doppia pretesa di istruire e divertire. Ogni discorso degli Africani riportato è soggetto a un'interpretazione. "Cette interprétation est heuristique car elle vise à ramener l'inconnu africain, matérialisé par l'étrangeté de sa langue, au connu européen, ce qui entraîne la réactivation indéfinie d'un même "régime de véridiction" sur les Africains» (p. 203). Spesso questa interpretazione porta con sé la volontà di adattare le parole degli Africani al gusto del pubblico francese.

La terza parte, «Fictionnalisation des dires de l'autre africain», si occupa invece di mettere in luce come gli Africani e le loro lingue vengano romanzati in veste di "Altro", qualcosa di diverso da ciò che è l'uomo francese. In particolar modo nella letteratura abolizionista, si cerca di dar voce al popolo africano, immaginando e creando possibili dialoghi tra colonizzatori e colonizzati, provando a costruire e a mettere in luce un personaggio solo che possa dar voce a un intero popolo di oppressi, ma commettendo forse l'ingenuo errore di pensare che una sola persona possa esprimere la volontà, $i$ sentimenti, i desideri di un'intera popolazione. Bellissime e molto interessanti sono, in quest'ultima parte, alcune immagini inserite dall'autore, che mostrano il modo in cui la popolazione nera veniva percepita e rappresentata nella Francia del Settecento.

Il saggio è molto ricco di informazioni, di esempi a sostegno della tesi dell'autore, che è estremamente preciso e puntuale nella descrizione di ogni singolo brano scelto. Il lettore riesce a crearsi un quadro molto ben definito delle dinamiche che regolavano i rapporti tra colonizzatori francesi e colonizzati africani. Questo permette di comprendere al meglio anche il modo giusto di approcciarsi ai racconti di viaggio del XVIII secolo, tenendo sempre ben presente chi ne erano gli autori. Tutta l'opera è scritta utilizzando un linguaggio preciso, ma accessibile a qualsiasi lettore, che viene affascinato dalla semplicità con cui l'autore riesce a toccare argomenti che, mai come oggi, sono così delicati. A conclusione dell'opera si trovano una ricchissima bibliografia, estremamente dettagliata, che ancora una volta dimostra la cura che l'autore ha messo nella stesura del testo, nonché due indici (Index des noms propres e Index des notions) molto ricchi e utili al lettore. 